\title{
Audit of Histopathology Reports for Breast Cancer in Aminu Kano Teaching Hospital
}

\author{
Vérification des rapports histopathologie du cancer du sein dans un hôpital \\ d'enseignement Aminu Kano
}

\section{A. T. Atanda*, J. O.Atanda}

\begin{abstract}
BACKGROUND: The usefulness of histopathology reports is a function of the quality of information contained therein. Thus there is need to establish minimum criteria to be met in reporting cases as a quality control mechanism.

OBJECTIVE: To audit the quality of histopathology reports of mastectomy specimens received in the pathology laboratory of a Teaching Hospital.

METHODS: Laboratory numbers of all cancer bearing mastectomy cases received in 10 years (1999-2008) were extracted from pathology reception registers and their accompanying original request cards were retrieved from archives. From these cards relevant information meeting six set audit criteria and average turn around times were determined and analysed.

RESULTS: One hundred and sixty-five mastectomy cases were received but archival retrieval was possible for only 134 $(\mathbf{8 1 . 2 \%})$ cases. The reports documented tumour size, macroscopic resection margin, histological tumour type, histological grading, lymphatic/vascular invasion characterized by invasion of tumour cells into lymphatic vessels, arteries or more importantly veins, and microscopic resection margin. These were documented in $50 \%, 62 \%$, $92 \%, 40 \%, 12 \%$ and $64 \%$ of cases respectively. Average turn around time was $\mathbf{1 5 . 8}$ days. Only three $(\mathbf{2 . 2 \%})$ of the reports met all the six criteria.

CONCLUSION: This 10-year audit shows the lapses in our histopathology reports and the need for establishment of standard report formats as tools for quality assurance. WAJM 2010; 29(3): 174-177.
\end{abstract}

Keywords: Clinical, Audit, Mastectomy, Northern Nigeria.

\section{RÉSUMÉ}

CONTEXTE: L'utilité des rapports est l'histopathologie en fonction de la qualité des informations qui y sont contenues. Ainsi il est nécessaire d'établir des critères minimaux à remplir signaler les cas comme un mécanisme de contrôle de la qualité. OBJECTIF: vérification de la qualité des rapports d'histopathologie mastectomie spécimens reçus dans le laboratoire de pathologie de un hôpital d'enseignement.

MÉTHODES: numéros d'Laboratoire de tous portant le cancer cas de mastectomie a reçu en 10 ans (1999-2008) ont été extraites de registres de réception et de leur pathologie d'accompagnement des cartes demande initiale ont été extraites de archives. A partir de ces cartes réunion d'information pertinentes six fois les critères de vérification mis et tourner autour de la moyenne ont été déterminées et analysées.

RÉSULTATS: Cent soixante-cinq cas ont été mastectomie reçues, mais la récupération d'archives a été possible pour seulement 134 (81,2\%) des cas. Les rapports documentés taille de la tumeur, Marge d'exérèse macroscopique, type histologique de la tumeur, grading histologique, lymphatique / invasion vasculaire caractérisée par l'invasion des cellules tumorales dans lymphatique navires, des artères ou des veines plus important, et microscopiques marge de résection. Ils ont été documentés dans $50 \%, 62 \%, 92 \%, 40 \%, 12 \%$ et $64 \%$ des cas respectivement. Moyenne tourner autour du temps était de 15,8 jours. Seulement trois (2,2\%) de la rapports satisfait à toutes les six critères.

CONCLUSION: La vérification de 10 ans montre les lacunes dans nos les rapports d'histopathologie et la nécessité d'établir des formats de rapport standard comme des outils d'assurance qualité. WAJM 2010; 29 (3): 174-177.

Mots clés: clinique, de l'audit, mammaires, le nord du Nigeria.

Department` of Pathology, Bayero University, Kano/Aminu Kano Teaching Hospital, Kano, PMB 3452, Kano.

Correspondence: Dr. A. T. Atanda, Departments of Pathology, Bayero University, Kano/Aminu Kano Teaching Hospital, Kano, PMB 3452, Kano. Postcode 700001, Tel No. 08035975951 E-mail: dtahija@yahoo.com 


\section{INTRODUCTION}

The need for Clinical Audit as a tool for ensuring quality of laboratory output in laboratories has been well recognized. ${ }^{1}$ The benefits to the practice of laboratory medicine and improved patient care are also indisputable. Yet most laboratories in Nigeria have failed to implement a structured audit scheme to give life to this concept. ${ }^{2}$

The first historically documented audit activity in clinical practice is credited to Florence Nightingale during the Crimean War of 1853-1855. Appalled by the high mortality rates in the military hospital she employed a methodical approach to patient care as well as laying emphasis on uniformity and comparability of results of health care. With this change in approach she lowered mortality from $40 \%$ to $2 \% .^{3}$ Another historical figure worthy of mention is Ernest Codman, an American. He is reported to be the first true medical auditor following his work in 1912 on monitoring surgical outcomes. He envisioned quality monitoring and assurance for efficient patient management. ${ }^{3}$

The definition, concept and prefixes attached to the word "Audit" relative to medical practice have evolved over the years. In 1989, in the United Kingdom, following recognition of the need to integrate audit activity into medical practice a White Paper entitled Working for patients was released. In this paper the term "medical audit" was introduced, and it was defined as: "the systematic critical analysis of the quality of medical care including the procedures used for diagnosis and treatment, the use of resources and the resulting outcome and quality of life for the patient." 4

However, in 1993 following broadening of the spectrum of audit activities captured by the term "Medical audit" the concept of "Clinical Audit" then evolved and a revised definition was introduced by the National Institute for Health and Clinical Excellence (NICE) in UK in a published paper: Principles for Best Practice in Clinical Audit. In this paper clinical audit is defined as: " $a$ quality improvement process that seeks to improve patient care and outcomes through systematic review of care against explicit criteria and the implementation of change...." 5

The process of Clinical audit is a cyclical or spiral pattern and involves five important steps: ${ }^{6}$ (1) identification of a problem or issue. This may be accomplished by collective brainstorming by stakeholders as well as collection of data on past practice; (2) criteria and standards definition. These serve as the yard stick against which future performances are evaluated; (3) observation and data collection of ongoing practice; (4) comparison of performance with established standards. The improvements noted in practice relative to set standards however have been shown to exhibit the Hawthorn effect ${ }^{7}$ which attributes improvement in practice to the awareness of being observed during data collection. This has been shown to be minimal if data collection is subtle and attention is not deliberately drawn to the audit activity; ${ }^{8}$ and (5) implementation of changes. Following implementation of changes the cyclical process recommences. The effectiveness of clinical audit has been shown to be more obvious the further the current practice is from the set standards. ${ }^{6}$

This study aimed to audit the quality of information contained in the histopathology reports of mastectomy specimens received in the Pathology laboratory of Aminu Kano Teaching Hospital, Kano between 1st January, 1999 and $31^{\text {st }}$ December, 2008 and to establish a baseline for comparison of future clinical audit activities.

\section{MATERIALS AND METHODS}

Location of study: This audit activity was carried out in the Histopathology Department of Aminu Kano Teaching Hospital, Kano, Northwestern Nigeria and it spans a period of 10 years (1999-2008).

Choice of indicators: The choice of six criteria utilized in this audit activity is based on results of literature search..$^{9,10}$ These items, with the exception of immunohistochemcal assessment omitted in this study because it has only recently become available, have been shown to be vital in the management of patients with breast cancer. Thus these were assessed for their inclusion in histopathology reports for the years under review in addition to assessment of the laboratory's turn-around-time. The seven parameters included: tumour size in at least one dimension; distance of tumour from at least one resection margin; histologic tumour type; histologic grading (modified Blooms and Richardson); presence or absence of lymphatic and/or vascular invasion; histologic status of the resection margins; and the turn around time.

\section{Inclusion and exclusion criteria:} All simple, modified radical and radical mastectomy specimens were included in the audit while all specimens from lumpectomy, quadrantectomy, segmental resection, partial mastectomy, tylectomy and residual tumour were excluded. Cases with missing archival material were also excluded from the audit.

Data Retrieval: Cases meeting the inclusion criteria were obtained from the departmental specimen register and original forms accompanying them were retrieved from archives. From these forms data were extracted on the completeness of the macroscopic and microscopic information provided relative to the set audit criteria.

Number Analyzed: One hundred and sixty-five specimens meeting the inclusion criteria were received and analyzed during the 10-year period but complete archival records were available for only 134 (81.2\%) cases. Data management and analysis was done with SPSS 16.0 version.

\section{RESULTS}

In the period covered by this audit 165 mastectomy specimens meeting the inclusion criteria were retrieved but records were available for only 134 $(81.2 \%)$. The annual number of mastectomy cases increased progressively from five in 1999 to 24 in 2008 As shown in Table 1 the most frequently mentioned feature in the surgical pathology reports was the histologic tumour type described in 123 (92\%) of cases while the least mentioned feature was presence or absence of vascular or lymphatic invasion. Tumour size was measured in only $67(50 \%)$ cases, macroscopic resection margin, aided by painting or tagging, in $83(62 \%)$, 
Table 1: Ddistribution of Cases by Audit Criteria

\begin{tabular}{lr}
\hline Criterion & Number(\%) \\
\hline Tumour size & $67(50)$ \\
Distance from resection & \\
Margin & $83(62)$ \\
Histologic Tumour type & $123(92)$ \\
Histologic grading & $53(40)$ \\
Lympho-vascular invasion & $16(12)$ \\
Histologic Resection Margin & $86(64)$ \\
$*$ Average Turn-Around-Time & 15.8 \\
\hline * Mean value in days. &
\end{tabular}

microscopic resection margin in $86(64 \%)$ and histologic grading in $53(40 \%)$ cases. Only $3(2.2 \%)$ of all our reports met all the requirements of the audit criteria. Annual mean turn around time ranged from $6.2-$ 22.7 days with an overall average of 15.8 days. No remarkable temporal trends were noted in the documentation of any of these parameters in the ten years studied.

\section{DISCUSSION}

The necessity for continuous clinical audit in anatomic pathology or histopathology and cytopathology cannot be overemphasized. In Nigeria the Medical and Dental Council of Nigeria (MDCN) is the body charged with the responsibility of monitoring laboratory performance but as noted by Ojo et $a l^{2}$ the practice of clinical audit is yet to be entrenched in pathology laboratory set up nation-wide.

The implementation of sustainable clinical audit mechanisms in any laboratory would primarily require a thorough assessment of its performance in the years preceding the setting of standards. ${ }^{6}$ This would enable it to identify its strengths and weaknesses and thus be able to determine areas on which to focus its corrective strategies. The ultimate focus of such a laboratory would be improved and sustainable quality of service to its clients, the clinicians. It may require the laboratory to identify those aspects of its services that are most frequently demanded by its clients or those in which laboratory errors are associated with grievous consequences. The choice to highlight the quality of breast cancer reports that have emanated from our histopathology laboratory in AKTH stems from this need for quality assurance.

Breast cancer has become the most common female cancer worldwide and in parts of Nigeria it is competing strongly in ranking with cervical cancer as the most common female cancer. ${ }^{11,12}$ Thus the need to standardize histopathology reports so as to ensure that information contained therein is promptly delivered and of clinical relevance for optimum patient care.

Breast cancer pathology reporting has been found to be associated with wide inter-laboratory variations. ${ }^{13}$ Key elements that affect treatment are sometimes not included in these reports and these often contribute to delays in and suboptimal patient management. ${ }^{13}$ The recognition of these variations in reporting has led to the adoption of standardized formats as instruments of quality control and assurance. The need for such quality control measures resulted in formulation of specific recommendations for breast cancer reporting by the Australian Cancer Network in 1995 and similarly led the Breast Tumor Panel of the Canadian Reference Centre for Cancer Pathology in the same year to distribute guidelines for reporting cancer specimens. ${ }^{14,15}$

Relative to what obtains in developed countries our laboratory is currently at a stage comparable to that in most laboratories in Australia in 1995 before the release of specific recommendations for breast cancer reporting. Prior to the release of the recommendations tumour type and size were found to be given in reports of invasive breast cancer for $93 \%$ of women, $70 \%$ had, in addition, grade and clearance of the margins while only $28 \%$ had all recommended information. ${ }^{16}$ In comparison our reports documented tumour type in $92 \%$ of cases but only documented tumour size in $50 \%$ of cases. The presence or absence of tumour cells in the resection margin, which determines the completeness or otherwise of surgical procedure, was documented in only $64 \%$ of our cases. Only 3 (2.2\%) of all our reports met all the requirements of the audit criteria. While tenable the observation that as a tertiary hospital laboratory trainee pathologist may be responsible for several of these omissions, it only serves to buttress the need to develop standardized formats for reporting of specific disease entities as well as ensuring competence of the trainees before being left to function on their own.

In none of the 134 mastectomy specimens audited in this study was the resection margin painted nor specimen oriented. Similar clinical omission was identified in $75 \%$ of specimens in an audit of cases in Buffalo, USA. ${ }^{13}$ Such omissions have also been shown to negatively limit the usefulness of pathology reports.

The usefulness of pathology reports rely mainly on the information contained in them yet prompt delivery of such reports is of no less significance. The promptness of report delivery determines not only the rapidity with which clinical decisions can be made but also by extension the lengths of patient hospital stay. These clinical considerations are in part governed by the laboratory turn around time. An average TAT of 15.8 days was found for our mastectomy specimens. This is over twice the maximum duration stipulated in the Service Delivery Charter document drawn up by the department for all surgical pathology specimens. The shortest average yearly turn around time our laboratory achieved for mastectomy specimens was 6.2 days. Factors responsible for this include peculiar inherent and extraneous laboratory inputs.

Our centre, for most of the 10 audited years had two full-time Pathologists, four trainee pathologists, two Technologists and one typist. Most of the delays in our centre which is semiautomated have been attributed to poor power supply needed to run various stages of the tissue processing including typing of results which accounted for most of the delay. Inadequate and improperly filled request forms have also constituted another cog in the wheel of prompt service delivery in our centre. Malami and Iliyasu ${ }^{17}$ in an earlier study of quality assurance in this hospital, Kano found inadequacy of clinical data on request cards in $28.9 \%$ of 58 cases 
studied in an audit activity. Omission of surgeons' names and/or telephone numbers from request forms has several times prevented signing out of cases where additional information is required and thus contributing to lengthy turn around times.

While Appleton and colleagues ${ }^{18}$ in their observations on the biennial auditing of mastectomy reports concluded that successive rounds of audit increases the standard of reporting in histopathology, Wilkinson and colleagues $^{13}$ relating their findings of falling compliance with College of American Pathologists guidelines in the United States, however caution that passive distribution alone might not be sufficient to accomplish laboratory-wide quality improvement in breast pathology reporting. They concluded that even though it is important to ensure all pathologists adhere to these report formats there is a need to put mechanisms in place to monitor compliancAs similar suggestion was also made by Appleton and colleagues ${ }^{18}$ about the need for continuous monitoring of standards as these may deteriorate over time.

\section{Recommendations}

For the improvement of quality of histopathology report for breast cancer (and all pathology reports in general) in laboratories across the country it is necessary to implement the following steps:

- Close monitoring of trainee Pathologists by senior colleagues in the various accredited centres.

- Close collaboration between Pathologists and Surgeons to ensure internal quality assurance.

- Close collaboration between laboratories within and outside Nigeria to facilitate inter-laboratory quality assurance
- $\quad$ Need for pathologists to formulate minimal criteria for histopathological reports of breast cancers and other tumours. This could be done by the Association of Pathologists of Nigeria (ASOPON) or the National Postgraduate Medical College of Nigeria (NPMCN) which would require periodic evidences of participation in clinical audit by each fellow of the college of Pathologists.

In conclusion this 10-year audit of histopathology reports of mastectomy specimens from invasive breast cancers in AKTH, Kano has shown the need for establishment of standard report formats as tools of quality assurance, the need for provision of better working conditions in Nigerian laboratories to ensure short turn around times and the need for better record keeping for ease of retrieval.

\section{REFERENCES}

1. Scally G, Donaldson LJ. Clinical governance and the drive for quality improvement in the new NHS in England. BMJ 1998; 317: 61-5.

2. Ojo OS, Olasode BJ, Lawal AA. Medical audit and clinical laboratory practice in Nigeria. Niger Med J 1996; 31: 36-37.

3. Retrieved from "http://en.wikipedia. org/wiki/Clinical_audit" Retrieved 16 June, 2009.

4. NHS Executive, Promoting clinical effectiveness. A framework for action in and through the NHS. London: NHS Executive, 1996.

5. National Institute of Clinical Excellence, Principles of Best Practice in Clinical Audit. London: NICE, 2002. (ISBN 185775-976-1).

6. Benjamin A. Audit: how to do it in Practice. BMJ 2008; 336: 1241-1245.

7. Cook TD, Compbell DT. QuasiExperimentation: Design and Analysis Issues for Field Settings. Boston, Mass: Houghton-Mifflin; 1979.

8. Wright E. Author's Response. J Am Dent Assoc 2000; 131: 560-561.
9. Association of Directors of Anatomic and Surgical Pathology recommendations for the reporting of breast Carcinoma. Mod Pathol 1996; 9: 7781.

10. Connolly J. Recommendations for the reporting of breast carcinomas. Pathol Case Rev 1998; 3: 241-247.

11. Mandong BM, Madaki AKJ, Manasseh AN, Malignant diseases in Jos: A follow-up. Annals of African Medicine 2003; 2: 49-53.

12. Mohammed AZ, Edino ST, Ochicha O, Gwarzo AK, Samaila AA. Cancer in Nigeria: A 10-Year Analysis of the Kano Cancer Registry. Niger J Med 2008; 17: 280-284.

13. Wilkinson NW, Shahryarinejad A, Winston JS, Watroba N, Edge SB. Concordance with breast cancer pathology reporting practice guidelines. J Am Coll Surg. 2003; 196: 38-43.

14. The pathology reporting of breast cancer. A guide for pathologists, surgeons, radiologists and oncologists. Recommendations of the Australian Cancer Network Working Party. 1st ed. 1995.

15. National Coordinating Group for Breast Screening Pathology. Pathology reporting in breast cancer screening. NHSBSP publication no. 3, 1995. ISBN 1871997224.

16. Kricker A, Armstrong B, Smith C, Bilous M, Camaris C, Mayer A, Psarianos T. An audit of breast cancer pathology reporting in Australia in 1995. Br J Cancer 1999; 80: 563-8.

17. Malami SA, Iliyasu Y. Local Audit of Diagnostic Surgical Pathology as a Tool of Quality Assurrance. Niger J Med 2008; 17: 186-190.

18. Appleton MA, Douglas-Jones AG, Morgan JM. Evidence of effectiveness of clinical audit in improving histopathology reporting standards of mastectomy specimens. J Clin Pathol. 1998; 51: 30-3.

\section{Conflict of Interest Declaration}

The authors of this paper have no conflicts of interest with or commitment to any body or organization, either financially or otherwise. 